\title{
Estimating age-based antiretroviral therapy costs for HIV-infected children in resource-limited settings based on World Health Organization weight-based dosing recommendations
}

\author{
Kathleen Doherty ${ }^{1 *}$, Shaffiq Essajee ${ }^{2,3}$, Martina Penazzato ${ }^{4}$, Charles Holmes ${ }^{5}$, Stephen Resch ${ }^{6}$
} and Andrea Ciaranello ${ }^{7 *}$

\begin{abstract}
Background: Pediatric antiretroviral therapy (ART) has been shown to substantially reduce morbidity and mortality in HIV-infected infants and children. To accurately project program costs, analysts need accurate estimations of antiretroviral drug (ARV) costs for children. However, the costing of pediatric antiretroviral therapy is complicated by weight-based dosing recommendations which change as children grow.

Methods: We developed a step-by-step methodology for estimating the cost of pediatric ARV regimens for children ages $0-13$ years old. The costing approach incorporates weight-based dosing recommendations to provide estimated ARV doses throughout childhood development. Published unit drug costs are then used to calculate average monthly drug costs. We compared our derived monthly ARV costs to published estimates to assess the accuracy of our methodology.

Results: The estimates of monthly ARV costs are provided for six commonly used first-line pediatric ARV regimens, considering three possible care scenarios. The costs derived in our analysis for children were fairly comparable to or slightly higher than available published ARV drug or regimen estimates.

Conclusions: The methodology described here can be used to provide an accurate estimation of pediatric ARV regimen costs for cost-effectiveness analysts to project the optimum packages of care for HIV-infected children, as well as for program administrators and budget analysts who wish to assess the feasibility of increasing pediatric ART availability in constrained budget environments.
\end{abstract}

Keywords: Antiretroviral therapy, Pediatric HIV, Costs

\section{Background}

Currently, 3.4 million children are living with HIV throughout the world [1]. Early antiretroviral therapy (ART) has been shown to reduce morbidity and mortality by $75 \%$ in infants infected with HIV [2], yet only approximately $28 \%$ of HIV-infected children in need of treatment are estimated to be receiving ART [3]. Massive scale-up of pediatric HIV treatment is needed to prevent

\footnotetext{
*Correspondence: kdoherty6@partners.org; aciaranello@partners.org ${ }^{1}$ Medical Practice Evaluation Center, Divisions of General Medicine, Massachusetts General Hospital, Boston, MA, USA

${ }^{7}$ Medical Practice Evaluation Center, Divisions of General Medicine and Infectious Disease, Massachusetts General Hospital, Boston, MA, USA Full list of author information is available at the end of the article
}

mortality and control the pediatric HIV epidemic, at a time when resources for HIV care are increasingly constrained [4].

To inform the scale-up of pediatric HIV care in the context of budget constraints, policy makers need accurate projections of antiretroviral drug (ARV) costs and a clear analysis of the cost-effectiveness of alternative ART strategies [5-8]. There are four key issues in the estimation of ART costs for children. First, specific medications, such as lopinavir/ritonavir (LPV/r) and abacavir (ABC), may be preferred in guidelines for clinical reasons [9-12], but their costs remain higher as well. Second, fixed-dose combinations (FDCs) are widely used in many ART programs and

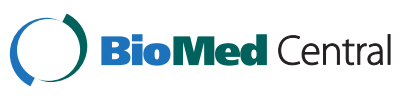


often lead to substantial cost-savings compared to their individual component drugs, as well as dosing convenience and improved adherence [13-15]. The production of pediatric FDCs has improved drastically over the past few years, resulting in several dual and triple dispersible formulations $[7,16]$. However, access to these formulations remains limited in many programs $[17,18]$. Third, many medications are not formulated for easy administration to infants and very young children, who cannot yet swallow pills. Such children require either dispersible tablets or syrup formulations, which are often more expensive than tablets of the same medication, and in the case of syrups may be less palatable, compromising adherence and efficacy [19]. Finally, national and international recommendations regarding pediatric ART treatment are in transition. Although the WHO publishes guidelines on pediatric HIV treatment, differences in first and second line treatment regimens exist between Asian and African care settings [20]. Additionally, discrepancies between preferred regimens exist within individual countries between different programs or clinics. In general, programs recommend that children are transitioned away from syrups to solid formulations as soon as they are able to tolerate them. This reduces costs, but local clinical practice may differ from the national recommendation.

Pediatric antiretroviral therapy use is further complicated by the need for increasing drug doses as children grow. Patients must be consistently monitored for changes in weight to ensure that they are receiving adequate doses of each drug to reach therapeutic levels and fully suppress the virus, while also avoiding toxicities related to excess dosing [21]. To evaluate the costs and cost-effectiveness of various ARV regimens analysts need a defined methodology for calculating monthly ARV costs that incorporates this need for dose modification, but a simple method to estimate weight-based costs is not widely available. In 2005, the Clinton Health Access Initiative (CHAI) developed a forecasting tool for pediatric ART which has primarily been used to help countries determine the cost of pediatric treatment targets and as a tool for ARV procurement planning. The tool estimates the quantities of ARVs needed based on the makeup of the patient population and then allows program managers to input current drug pricing to create a full ARV program budget. However, CHAI's model has not been published to date. Two published studies have also examined pediatric HIV treatment costs. One reports the average cost of HIV treatment care across 43 PEPFAR sites, where $7 \%$ of the study population were pediatric patients [22]. Meyer-Rath et al. completed a similar analysis for two dedicated pediatric care sites in South Africa, and further calculated the proportion of total treatment costs pertaining to ART costs [23]. However, neither study broke down the cost of pediatric ART by age, weight or regimen.
Here, we propose a step-by-step approach for determining the monthly costs of ARV medications for children ages $0-13$ years in resource-limited settings. We use published ARV price lists as a basis, and account for changes in dosing as children grow, as well as the possible lack of availability of pediatric tablets or co-formulations in some settings and for some groups of patients. This methodology can be easily updated using a simple online tool as new ARV prices are released by international agencies $[24,25]$ or are negotiated by individual governments $[26,27]$ (see Additional file 1). We hope this approach can be used by investigators seeking to analyze the costeffectiveness of ART strategies for children, as well as by analysts and program administrators in accurately assessing the costs of potential treatment options for pediatric HIV patients.

\section{Methods}

To estimate the monthly cost of specific ART regimens for children ages $0-13$ years in resource-limited settings, we developed a 7-step approach.

1. Weight-based doses for pediatric ARV were taken from Annex E of the 2010 World Health Organization (WHO) Pediatric Guidelines and Annex 7 of the upcoming WHO 2013 Consolidated Pediatric and Adult Guidelines (Table 1) [7,28]. The WHO stratifies dosing recommendations by drug formulation and by current weight (divided into 7 weight bands: $3-5.9 \mathrm{~kg}, 6-9.9 \mathrm{~kg}, 10-13.9 \mathrm{~kg}$, $14-19.9 \mathrm{~kg}, 20-24.9 \mathrm{~kg}, 25-34.9 \mathrm{~kg}$, and $35+\mathrm{kg}$ ). We modeled dosing for all drugs that are currently recommended in the $2013 \mathrm{WHO}$ guidelines. We also included doses from the $2010 \mathrm{WHO}$ guidelines for drugs such as stavudine (d4T) that are no longer recommended, but still likely to be available in many pediatric treatment programs [7].

2. Assignment of unit costs for each antiretroviral drug (Table 2). We next identified publicly available unit costs for each medication. Unit costs are defined as cost (in 2012 USD) per tablet, per capsule or per milliliter of liquid formulation. Due to the wide variety of drug prices available to resource-limited countries based on individual agreements with pharmaceutical companies, we used the CHAI May 2012 ceiling price list as the basis for drug cost estimates [24]. These ceiling prices represent the highest level that pharmaceutical companies can charge for these brand-name products in the countries that are members of the CHAI Procurement Consortium, and thus that have access to the reduced costs drug costs negotiated by CHAI. As individual countries or programs may be able to negotiate or obtain access to lower 
Table 1 Weight-based dosing recommendations for currently recommended and commonly used antiretroviral drugs $[7,28]$

\begin{tabular}{|c|c|c|c|c|c|c|c|}
\hline \multirow[b]{2}{*}{ Medication (strength) } & \multicolumn{7}{|c|}{ WHO dosing recommendations by weight band } \\
\hline & $3-5.9 \mathrm{~kg}$ & $6-9.9 \mathrm{~kg}$ & $10-13.9 \mathrm{~kg}$ & $14-19.9 \mathrm{~kg}$ & $20-24.9 \mathrm{~kg}$ & $25-34.9 \mathrm{~kg}$ & $35+\mathrm{kg}$ \\
\hline $\mathrm{ABC}(20 \mathrm{mg} / \mathrm{ml})$ & $3 \mathrm{ml} \mathrm{bid}$ & $4 \mathrm{ml} \mathrm{bid}$ & $6 \mathrm{ml}$ bid & - & - & - & - \\
\hline ABC (60 mg) & 1 tab bid & 1.5 tab bid & 2 tab bid & 2.5 tab bid & 3 tab bid & - & - \\
\hline ABC (300 mg) & - & - & - & - & - & 1 tab bid & 1 tab bid \\
\hline $\mathrm{d} 4 \mathrm{~T}(1 \mathrm{mg} / \mathrm{ml})$ & $6 \mathrm{ml} \mathrm{bid}$ & $9 \mathrm{ml} \mathrm{bid}$ & - & - & - & - & - \\
\hline d4T (15 mg) & - & - & 1 tab bid & - & - & - & - \\
\hline d4T (20 mg) & - & - & - & 1 tab bid & 1 tab bid & - & - \\
\hline $\mathrm{d} 4 \mathrm{~T}$ (30 mg) & - & - & - & - & - & 1 tab bid & 1 tab bid \\
\hline 3TC (10 mg/ml) & $3 \mathrm{ml} \mathrm{bid}$ & $4 \mathrm{ml} \mathrm{bid}$ & $6 \mathrm{ml} \mathrm{bid}$ & - & - & - & - \\
\hline 3TC (150 mg) & - & - & - & 0.5 tab bid & $1 \mathrm{tab} a m+0.5$ tab pm & 1 tab bid & 1 tab bid \\
\hline EFV (200 mg) & NR & $N R$ & 1 cap qd ( $\geq 3 y r s$ only) & 1.5 cap qd & 1.5 cap qd & 2 cap qd & - \\
\hline EFV (600 mg) & - & - & - & - & - & - & 1 tab qd \\
\hline LPV/r (80/20 mg/ml) & $1 \mathrm{ml}$ bid & $1.5 \mathrm{ml} \mathrm{bid}$ & $2 \mathrm{ml}$ bid & $2.5 \mathrm{ml} \mathrm{bid}$ & $3 \mathrm{ml} \mathrm{bid}$ & - & - \\
\hline LPV/r (100/25 mg) & NR & $N R$ & 2 tab am + 1 tab pm & 2 tab bid & 2 tab bid & 3 tab bid & - \\
\hline LPV/r (200/50 mg) & - & - & - & - & - & - & 2 tab bid \\
\hline NVP (10 mg/ml) & $5 \mathrm{ml} \mathrm{bid}$ & $8 \mathrm{ml} \mathrm{bid}$ & $10 \mathrm{ml} \mathrm{bid}$ & - & - & - & - \\
\hline NVP (50 mg) & 1 tab bid & 1.5 tab bid & 2 tab bid & 2.5 tab bid & 3 tab bid & - & - \\
\hline NVP (200 mg) & - & - & - & - & - & 1 tab bid & 1 tab bid \\
\hline ZDV (10 mg/ml) & $6 \mathrm{ml} \mathrm{bid}$ & $9 \mathrm{ml}$ bid & $12 \mathrm{ml} \mathrm{bid}$ & - & - & - & - \\
\hline ZDV (60 mg) & 1 tab bid & 1.5 tab bid & 2 tab bid & 2.5 tab bid & 3 tab bid & - & - \\
\hline ZDV (300 mg) & - & - & - & - & - & 1 tab bid & 1 tab bid \\
\hline ZDV/3TCA $(60 \mathrm{mg} / 30 \mathrm{mg})$ & 1 tab bid & 1.5 tab bid & 2 tab bid & 2.5 tab bid & 3 tab bid & - & - \\
\hline ZDV/3TCA $(300$ mg/150 mg) & - & - & - & - & - & 1 tab bid & 1 tab bid \\
\hline $\begin{array}{l}\text { ZDV/3TC/NVP } \\
(60 \mathrm{mg} / 30 \mathrm{mg} / 50 \mathrm{mg})\end{array}$ & 1 tab bid & 1.5 tab bid & 2 tab bid & 2.5 tab bid & 3 tab bid & - & - \\
\hline $\begin{array}{l}\text { ZDV/3TC/NVPB } \\
(300 \mathrm{mg} / 150 \mathrm{mg} / 200 \mathrm{mg})\end{array}$ & - & - & - & - & - & 1 tab bid & 1 tab bid \\
\hline $\mathrm{d} 4 \mathrm{~T} / 3 \mathrm{TC}(6 \mathrm{mg} / 30 \mathrm{mg})^{\mathrm{C}}$ & 1 tab bid & 1.5 tab bid & 2 tab bid & 2.5 tab bid & 3 tab bid & - & - \\
\hline $\mathrm{d} 4 \mathrm{~T} / 3 \mathrm{TC}^{\mathrm{C}}(30 \mathrm{mg} / 150 \mathrm{mg})$ & - & - & - & - & - & 1 tab bid & 1 tab bid \\
\hline $\mathrm{d} 4 \mathrm{~T} / 3 \mathrm{TC} / \mathrm{NVP} \mathrm{P}^{\mathrm{D}}(6 \mathrm{mg} / 30 \mathrm{mg} / 50 \mathrm{mg})$ & 1 tab bid & 1.5 tab bid & 2 tab bid & 2.5 tab bid & 3 tab bid & - & - \\
\hline $\begin{array}{l}\text { d4T/3TC/NVPD } \\
(30 \mathrm{mg} / 150 \mathrm{mg} / 200 \mathrm{mg})\end{array}$ & - & - & - & - & - & 1 tab bid & 1 tab bid \\
\hline $\mathrm{ABC} / 3 \mathrm{TC}^{\mathrm{E}}(60 \mathrm{mg} / 30 \mathrm{mg})$ & 1 tab bid & 1.5 tab bid & 2 tab bid & 2.5 tab bid & 3 tab bid & - & - \\
\hline $\mathrm{ABC} / 3 \mathrm{TC}^{\mathrm{E}}(600 \mathrm{mg} / 300 \mathrm{mg})$ & - & - & - & - & - & 0.5 tab bid & 0.5 tab bid \\
\hline
\end{tabular}

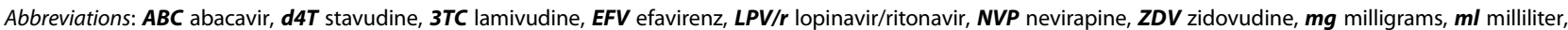
bid twice daily, $\boldsymbol{q d}$ once daily, $\boldsymbol{N R}$ not recommended, $\boldsymbol{t a b}$ tablet, cap capsule, $\boldsymbol{k g}$ kilogram.

A. Pediatric tablet is scored and can be split. Can be crushed and contents mixed with a small amount of water or food and taken immediately.

B. Pediatric tablet is dispersible and may be split. Can be dispersed into a small volume of water and mixed into a small amount of food and taken immediately.

C. Pediatric tablet is dispersible and crushable, can be split.

D. Pediatric tablet is dispersible and crushable, can be split. If unable to swallow, disperse 1 tablet in 2 teaspoons of water.

E. Pediatric tablet is scored and can be split. Can be crushed and contents mixed with a small amount of water or food and taken immediately.

prices for certain formulations, the unit costs shown here should be taken as a maximum estimate of drug costs in resource-limited settings. For the formulations not included in the CHAI 2012 price list, we used the price list from Mèdecins Sans
Frontières (MSF), and chose the price estimate for the generic version of the drug formulation if available [25]. Any other price list could be substituted for this source of data, including prices negotiated by other international agencies or 
Table 2 Unit costs, derived from CHAI 2012 Price List [24]

\begin{tabular}{|c|c|}
\hline Medication (strength) & Unit cost (2012 USD) \\
\hline $\mathrm{ABC}(20 \mathrm{mg} / \mathrm{ml})$ & $\$ 0.06 / \mathrm{ml}$ \\
\hline $\mathrm{ABC}(60 \mathrm{mg})$ & $\$ 0.09 / \mathrm{tab}$ \\
\hline ABC (300 mg) & $\$ 0.26 / \mathrm{tab}$ \\
\hline $\mathrm{d} 4 \mathrm{~T}(1 \mathrm{mg} / \mathrm{ml})$ & $\$ 0.01 / \mathrm{tab}$ \\
\hline d4T (15 mg) & $\$ 0.02 / \mathrm{tab}$ \\
\hline $\mathrm{d} 4 \mathrm{~T}$ (20 mg) & $\$ 0.02 / \mathrm{tab}$ \\
\hline d4T (30 mg) & $\$ 0.03 / \mathrm{tab}$ \\
\hline 3TC (10 mg/ml) & $\$ 0.01 / \mathrm{ml}$ \\
\hline 3TC (150 mg) & $\$ 0.04 / \mathrm{tab}$ \\
\hline EFV (200 mg) & $\$ 0.11 /$ cap \\
\hline EFV (600 mg) & $\$ 0.15 / \mathrm{tab}$ \\
\hline LPV/r (80/20 mg/ml) & $\$ 0.19 / \mathrm{ml}$ \\
\hline LPV/r (100/25 mg) & $\$ 0.14 / \mathrm{tab}$ \\
\hline LPV/r (200/50 mg) & $\$ 0.26 / \mathrm{tab}$ \\
\hline $\mathrm{NVP}(10 \mathrm{mg} / \mathrm{ml})$ & $\$ 0.01 / \mathrm{ml}$ \\
\hline NVP (50 mg) & $\$ 0.05 / \mathrm{tab}^{\mathrm{A}}$ \\
\hline NVP (200 mg) & $\$ 0.05 / \mathrm{tab}$ \\
\hline ZDV $(10$ mg/ml) & $\$ 0.01 / \mathrm{ml}$ \\
\hline ZDV (60 mg) & $\$ 0.05 / \mathrm{tab}^{\mathrm{B}}$ \\
\hline ZDV (300 mg) & $\$ 0.12 / \mathrm{tab}$ \\
\hline ZDV/3TC (60 mg/30 mg) & $\$ 0.05 / \mathrm{tab}$ \\
\hline ZDV/3TC (300 mg/150 mg) & $\$ 0.15 / \mathrm{tab}$ \\
\hline ZDV/3TC/NVP (60 mg/30 mg/50 mg) & $\$ 0.07 / \mathrm{tab}$ \\
\hline ZDV/3TC/NVP (300 mg/150 mg/200 mg) & $\$ 0.19 / \mathrm{tab}$ \\
\hline $\mathrm{d} 4 \mathrm{~T} / 3 \mathrm{TC}(6 \mathrm{mg} / 30 \mathrm{mg})$ & $\$ 0.03 / \mathrm{tab}$ \\
\hline d4T/3TC (30 mg/150 mg) & $\$ 0.06 / \mathrm{tab}$ \\
\hline $\mathrm{d} 4 \mathrm{~T} / 3 \mathrm{TC} / \mathrm{NVP}(6 \mathrm{mg} / 30 \mathrm{mg} / 50 \mathrm{mg})$ & $\$ 0.04 / \mathrm{tab}$ \\
\hline d4T/3TC/NVP (30 mg/150 mg/200 mg) & $\$ 0.11 /$ tab \\
\hline $\mathrm{ABC} / 3 \mathrm{TC}(60 \mathrm{mg} / 30 \mathrm{mg})$ & $\$ 0.09 / \mathrm{tab}$ \\
\hline $\mathrm{ABC} / 3 \mathrm{TC}(600 \mathrm{mg} / 300 \mathrm{mg})$ & $\$ 0.58-\$ 1.07 / \mathrm{tab}^{\mathrm{C}}$ \\
\hline
\end{tabular}

Abbreviations: ABC abacavir, d4T stavudine, 3TC lamivudine, EFV efavirenz, LPV/r lopinavir/ritonavir, NVP nevirapine, $Z \mathbf{D V}$ zidovudine, $\boldsymbol{m g}$ milligrams, $\mathbf{m l}$ milliliter, tab tablet, cap capsule.

A. Cost for NVP $(50 \mathrm{mg})$ not reported in CHAl Price List. Mèdecins San Frontières (MSF) reports a cost of $\$ 0.05 /$ tab from manufacturer Aurobindo [25] B. Cost for ZDV $(60 \mathrm{mg})$ not reported in 2012 CHAl Price List. MSF reports a cost of $\$ 0.05 /$ tab from manufacturer Ranbaxy [25].

C. Cost for ABC/3TC $(600 \mathrm{mg} / 300 \mathrm{mg})$ not reported in 2012 CHAl Price List. MSF reports a cost of $\$ 0.58-\$ 1.07 /$ tab from manufacturers ViiV, Aurobindo, Cipla and Matrix [25]

national governments [29]. This analysis includes only the costs of drug products themselves, and excludes the costs of shipping, or any costs related to the delivery of ART, such as equipment, personnel, overhead, or wasting.

3. Calculation of monthly costs for each medication by weight (Table 3). Assuming an average of 30.4 days in a month, we calculate the monthly cost for each medication by WHO weight band as follows:

$$
\begin{aligned}
\text { Monthly cost }= & \text { Average dose per day } * \\
& \text { unit cost per drug } * \\
& 30.4 \text { days per month }
\end{aligned}
$$

Average daily dose (in mg, ml, tablet, or capsule/ day) is found in Table 2 and unit cost (in USD $/ \mathrm{mg}$, $\mathrm{ml}$, tablet, or capsule) is found is Table 3 for each of the drugs in this analysis.

\section{Probability of being in each WHO weight band by} age (Table 4). Although most clinical guidelines regarding ARV dosing recommendations are based on a child's weight, rather than current age [17], most policy recommendations, such as the WHO criteria for ART initiation, are based on a child's age at presentation to care [7]. Thus, it is useful to translate the weight-based ARV costs calculated in Step 3 (Table 3) into age-based ARV costs. Weight-by-age distributions were obtained from the WHO Child Growth Standards for children $<5$ years of age and from the Centers for Disease Control and Prevention (CDC) Growth Charts for children $\geq 5$ years [30,31]. Both growth charts contain the Lambda-Mu-Sigma (LMS) parameters (the power in the Box-Cox transformation (L), the median (M), and the generalized coefficient of variation $(\mathrm{S})$ ) needed to generate exact percentiles and z-scores by age and gender [32].

Although few data are available on how the weight distribution of HIV-infected children compares to the weight distribution of the general population of children the same age, one study found that on average, HIV-infected children are of lower weight [33]. To account for lower weights among HIV-infected children than among the general population, we first shifted the weight distribution in the growth charts to a $-1.5 \mathrm{z}$-score $(\mathrm{Z})$ and assumed the coefficient of variation of the weight distribution $\left(\mathrm{S}_{\mathrm{HIV}}\right)$ was equal to that of the general population. To examine the impact of these assumptions, we conducted sensitivity analyses in which we recalculated drug costs after varying both the shifted weight distribution z-score ( $\mathrm{z}$-scores of -3 to 0 ) and the coefficient of variation (double and half $\mathrm{S}_{\text {HIV }}$ ). These parameters can also be modified by use of the online tool.

Using these new weight-by age distributions, we calculated Z-scores for the upper and lower bounds of the weight bands used in the WHO dosing recommendations $(3 \mathrm{~kg}, 5.9 \mathrm{~kg}, 6 \mathrm{~kg}, 9.9 \mathrm{~kg}, 10 \mathrm{~kg}$, $13.9 \mathrm{~kg}, 14 \mathrm{~kg}, 19.9 \mathrm{~kg}, 20 \mathrm{~kg}, 24.9 \mathrm{~kg}, 25 \mathrm{~kg}$, and 
Table 3 Monthly costs for key antiretroviral drugs by weight

\begin{tabular}{|c|c|c|c|c|c|c|c|}
\hline \multirow[b]{2}{*}{ Medication (strength) } & \multicolumn{7}{|c|}{ Weight bands } \\
\hline & $3-5.9 \mathrm{~kg}$ & $6-9.9 \mathrm{~kg}$ & $10-13.9 \mathrm{~kg}$ & $14-19.9 \mathrm{~kg}$ & $20-24.9 \mathrm{~kg}$ & $25-34.9 \mathrm{~kg}$ & $35+\mathrm{kg}$ \\
\hline $\mathrm{ABC}(20 \mathrm{mg} / \mathrm{ml})$ & $\$ 10.94$ & $\$ 14.59$ & $\$ 21.89$ & - & - & - & - \\
\hline $\mathrm{ABC}(60 \mathrm{mg})$ & $\$ 5.47$ & $\$ 8.21$ & $\$ 10.94$ & $\$ 13.68$ & $\$ 16.42$ & - & - \\
\hline ABC (300 mg) & - & - & - & - & - & $\$ 15.81$ & $\$ 15.81$ \\
\hline $\mathrm{d} 4 \mathrm{~T}(1 \mathrm{mg} / \mathrm{ml})$ & $\$ 3.65$ & $\$ 5.47$ & - & - & - & - & - \\
\hline d4T (15 mg) & - & - & $\$ 1.22$ & - & - & - & - \\
\hline d4T (20 mg) & - & - & - & $\$ 1.22$ & $\$ 1.22$ & - & - \\
\hline d4T (30 mg) & - & - & - & - & - & $\$ 1.82$ & $\$ 1.82$ \\
\hline 3TC (10 mg/ml) & $\$ 1.82$ & $\$ 2.43$ & $\$ 3.65$ & - & - & - & - \\
\hline 3TC (150 mg) & - & - & - & $\$ 1.22$ & $\$ 1.82$ & $\$ 2.43$ & $\$ 2.43$ \\
\hline EFV (200 mg) & NR & NR & $\$ 3.34$ & $\$ 5.02$ & $\$ 5.02$ & $\$ 6.69$ & - \\
\hline EFV (600 mg) & - & - & - & - & - & - & $\$ 4.56$ \\
\hline LPV/r (80/20 mg/ml) & $\$ 11.55$ & $\$ 17.33$ & $\$ 23.10$ & $\$ 28.88$ & $\$ 34.66$ & - & - \\
\hline LPV/r (100/25 mg) & NR & NR & $\$ 12.77$ & $\$ 17.02$ & $\$ 17.02$ & $\$ 25.54$ & - \\
\hline LPV/r (200/50 mg) & - & - & - & - & - & - & $\$ 31.62$ \\
\hline NVP (10 mg/ml) & $\$ 3.04$ & $\$ 4.86$ & $\$ 6.08$ & - & - & - & - \\
\hline NVP (50 mg) & $\$ 2.74$ & $\$ 4.10$ & $\$ 5.47$ & $\$ 6.84$ & $\$ 8.21$ & - & - \\
\hline NVP (200 mg) & - & - & - & - & - & $\$ 3.04$ & $\$ 3.04$ \\
\hline ZDV (10 mg/ml) & $\$ 3.65$ & $\$ 5.47$ & $\$ 7.30$ & - & - & - & - \\
\hline ZDV (60 mg) & $\$ 3.04$ & $\$ 4.56$ & $\$ 6.08$ & $\$ 7.60$ & $\$ 9.12$ & - & - \\
\hline ZDV (300 mg) & - & - & - & - & - & $\$ 7.30$ & $\$ 7.30$ \\
\hline ZDV/3TC (60 mg/30 mg) & $\$ 3.04$ & $\$ 4.56$ & $\$ 6.08$ & $\$ 7.60$ & $\$ 9.12$ & - & - \\
\hline ZDV/3TC (300 mg/150 mg) & - & - & - & - & - & $\$ 9.12$ & $\$ 9.12$ \\
\hline ZDV/3TC/NVP (60 mg/30 mg/50 mg) & $\$ 4.26$ & $\$ 6.38$ & $\$ 8.51$ & $\$ 10.64$ & $\$ 12.77$ & - & - \\
\hline ZDV/3TC/NVP (300 mg/150 mg/200 mg) & - & - & - & - & - & $\$ 11.55$ & $\$ 11.55$ \\
\hline $\mathrm{d} 4 \mathrm{~T} / 3 \mathrm{TC}(6 \mathrm{mg} / 30 \mathrm{mg})$ & $\$ 1.82$ & $\$ 2.74$ & $\$ 3.65$ & $\$ 4.56$ & $\$ 5.47$ & - & - \\
\hline $\mathrm{d} 4 \mathrm{~T} / 3 \mathrm{TC}(30 \mathrm{mg} / 150 \mathrm{mg})$ & - & - & - & - & - & $\$ 3.65$ & $\$ 3.65$ \\
\hline d4T/3TC/NVP (6 mg/30 mg/50 mg) & $\$ 2.43$ & $\$ 3.65$ & $\$ 4.86$ & $\$ 6.08$ & $\$ 7.30$ & - & - \\
\hline d4T/3TC/NVP (30 mg/150 mg/200 mg) & - & - & - & - & - & $\$ 6.69$ & $\$ 6.69$ \\
\hline $\mathrm{ABC} / 3 \mathrm{TC}(60 \mathrm{mg} / 30 \mathrm{mg})$ & $\$ 5.47$ & $\$ 8.21$ & $\$ 10.94$ & $\$ 13.68$ & $\$ 16.42$ & - & - \\
\hline ABC/3TC (600 mg/300 mg) & - & - & - & - & - & $\$ 17.72-\$ 32.53$ & $\$ 17.72-\$ 32.53$ \\
\hline
\end{tabular}

Abbreviations: $\boldsymbol{A B C}$ abacavir, $\boldsymbol{d} \mathbf{4 T}$ stavudine, 3TC lamivudine, EFV efavirenz, LPV/r lopinavir/ritonavir, NVP nevirapine, ZDV zidovudine, $\boldsymbol{m g}$ milligrams, $\boldsymbol{m} \mathbf{I}$ milliliter, $\boldsymbol{N R}$ not recommended, $\boldsymbol{k g}$ kilogram.

$34.9 \mathrm{~kg}$ ). An automated calculation function in Excel was then used to convert the $\mathrm{z}$-scores into cumulative probability estimates. Finally, the probability of being in each weight band (by age and gender) was calculated as the cumulative probability of being above the upper bound of the weight band subtracted from the cumulative probability of being below the lower bound of the weight band (or the area under the curve within the upper and lower bounds). Assuming an equal proportion of males and females, these final probabilities by gender were averaged to estimate the probability of being in each weight band by age (Table 4).
5. Calculation of monthly costs for each medication by age (Table 5). We then used the newly defined probabilities of being in each weight band by age (Table 4) to calculate monthly medication costs by age. Monthly medication costs by age were calculated as the monthly medication cost by weight band (Table 3) multiplied by the probability of being in each weight band (Table 4). Several ARVs (such as $A B C$ ) have more than one formulation option recommended at each age. For these medications, we provide estimated monthly costs for two formulation options: 1) children initiate pediatric liquid formulations and then switch to pediatric 
Table 4 Probability of being in each WHO weight band by age

\begin{tabular}{|c|c|c|c|c|c|c|c|}
\hline \multirow[b]{2}{*}{ Age (years) } & \multicolumn{7}{|c|}{ Weight bands } \\
\hline & $3-5.9 \mathrm{~kg}$ & $6-9.9 \mathrm{~kg}$ & $10-13.9 \mathrm{~kg}$ & $14-19.9 \mathrm{~kg}$ & $20-24.9 \mathrm{~kg}$ & $25-34.9 \mathrm{~kg}$ & $35+\mathrm{kg}$ \\
\hline 0.5 & 0.246 & 0.754 & 0.000 & 0.000 & 0.000 & 0.000 & 0.000 \\
\hline 1 & 0.001 & 0.908 & 0.091 & 0.000 & 0.000 & 0.000 & 0.000 \\
\hline 2 & 0.000 & 0.285 & 0.706 & 0.009 & 0.000 & 0.000 & 0.000 \\
\hline 3 & 0.000 & 0.044 & 0.842 & 0.113 & 0.000 & 0.000 & 0.000 \\
\hline 4 & 0.000 & 0.003 & 0.593 & 0.398 & 0.005 & 0.000 & 0.000 \\
\hline 5 & 0.000 & 0.000 & 0.262 & 0.696 & 0.039 & 0.003 & 0.000 \\
\hline 6 & 0.000 & 0.000 & 0.070 & 0.779 & 0.135 & 0.016 & 0.001 \\
\hline 7 & 0.000 & 0.000 & 0.011 & 0.638 & 0.292 & 0.057 & 0.003 \\
\hline 8 & 0.000 & 0.000 & 0.001 & 0.403 & 0.439 & 0.147 & 0.010 \\
\hline 9 & 0.000 & 0.000 & 0.000 & 0.197 & 0.481 & 0.293 & 0.029 \\
\hline 10 & 0.000 & 0.000 & 0.000 & 0.073 & 0.390 & 0.464 & 0.073 \\
\hline 11 & 0.000 & 0.000 & 0.000 & 0.019 & 0.234 & 0.586 & 0.162 \\
\hline 12 & 0.000 & 0.000 & 0.000 & 0.003 & 0.096 & 0.591 & 0.310 \\
\hline 13 & 0.000 & 0.000 & 0.000 & 0.000 & 0.023 & 0.465 & 0.512 \\
\hline
\end{tabular}

Abbreviation: $\boldsymbol{k g}$ kilogram.

Weight-by-age standards were tabulated from the WHO Child Growth Standards for children $<5$ years and from the CDC Growth Charts for children ages $\geq 5$ years $[30,31]$. The equations used to generate these age-specific weight distributions rely on the Lambda-Mu-Sigma parameters: the median (M) weight, the generalized coefficient of variation (S), and the power in the Box-Cox transformation (L) [32,34]. To account for lower weights among HIV-infected children relative to the general population of same age, the age-specific weight distributions for HIV-infected children were shifted to the $-1.5 \mathrm{z}$-score of the general population distributions [33]. The HIV-infected median weight-for-age values $\left(M_{\text {HIV }}\right)$ were calculated at half-year intervals, where $M_{\text {HIV }}$ was equal to the value $M^{*}(1+L S Z){ }^{(1 / L)}$. The coefficient of variation $\left(\mathrm{S}_{\mathrm{HIV}}\right)$ was assumed to be equal to that of children of the same age in the general population. Z-scores for the upper and lower bounds of the WHO-specified weight intervals for ARV dosing ( $3 \mathrm{~kg}, 5.9 \mathrm{~kg}, 6 \mathrm{~kg}, 9.9 \mathrm{~kg}, 10 \mathrm{~kg}, 13.9 \mathrm{~kg}, 14 \mathrm{~kg}, 19.9 \mathrm{~kg}, 20 \mathrm{~kg}, 24.9 \mathrm{~kg}, 25 \mathrm{~kg}$, and $34.9 \mathrm{~kg})$ were calculated by

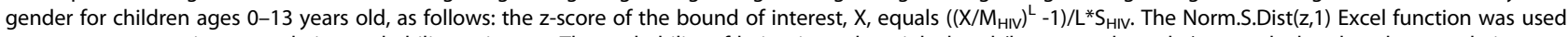
to convert z-scores into cumulative probability estimates. The probability of being in each weight band (by age and gender) was calculated as the cumulative probability of being below the upper bound of the weight band subtracted by the cumulative probability of being below the lower bound of the weight band (or the area under the curve within the upper and lower bounds). Results shown above assume an equal proportion of males and females.

then adult tablet formulations once liquids are no longer recommended or 2) children begin pediatric tablet formulations as soon as recommended, and then switch to adult tablet formulations once pediatric tablets are no longer recommended.

6. Calculation of monthly costs for complete medication regimens (Table 6). To determine the monthly costs of complete ART regimens, we combined the monthly costs by age for each of the component medications. The WHO 2013 HIV treatment guidelines currently recommend a first-line, PI-based regimen $(\mathrm{LPV} / \mathrm{r}+3 \mathrm{TC}+\mathrm{ABC}$ or $\mathrm{ZDV})$ for all HIV-infected children less than three years of age. However, previous WHO guidelines had recommended an NNRTI-based regimen for children who had not been exposed to NNRTIs to prevent mother-to-child transmissions, and in many countries, NNRTI-based regimens remain the most readily available first-line option for children. Here, we present examples of monthly regimen cost calculations for six commonly used ART regimens: lopinavir/ritonavir (LPV/r) with zidovudine (ZDV) and lamivudine (3TC), LPV/r with abacavir (ABC) and 3TC, LPV/r with stauvudine (d4T) and 3TC, nevirapine (NVP) or efavirenz (EFV) with $A B C$ and 3TC, NVP or EFV with ZDV and 3TC, and NVP or EFV with d4T and 3TC. Although d4T is no longer recommended as a first-line medication, it remains an option to use in case of anemia where access to $\mathrm{ABC}$ is limited; $\mathrm{d} 4 \mathrm{~T}$ is commonly used throughout Africa, largely because of its availability in inexpensive FDC formulations $[7,35]$.

For each regimen, we derived costs for three key scenarios that reflect setting-specific variations in the availability of co-formulated FDCs and the age at which children are assumed to transition from liquid to tablet formulations:

Scenario 1 (No FDCs, Late Switch): Coformulations are not available. Liquid formulations of all drug components are used until 4 years of age, and then children switch to pediatric/adult tablets as recommended by weight-based dosing. Scenario 2 (No FDCs, Early Switch): Coformulations are not available. Liquid 
Table 5 Monthly costs for antiretroviral drugs by age

\begin{tabular}{|c|c|c|c|c|c|c|c|c|c|c|c|c|c|c|}
\hline \multirow[b]{2}{*}{$\begin{array}{l}\text { Drug product } \\
\text { (Formulation) }\end{array}$} & \multicolumn{14}{|c|}{ Age (years) } \\
\hline & 0.5 & 1 & 2 & 3 & 4 & 5 & 6 & 7 & 8 & 9 & 10 & 11 & 12 & 13 \\
\hline$A B C^{A}$ & $\$ 13.70$ & $\$ 15.26$ & $\$ 19.74$ & $\$ 20.63$ & $\$ 18.57$ & $\$ 15.94$ & $\$ 14.65$ & $\$ 14.70$ & $\$ 15.23$ & $\$ 15.68$ & $\$ 15.89$ & $\$ 15.91$ & $\$ 15.86$ & $\$ 15.82$ \\
\hline$A B C^{B}$ & $\$ 7.54$ & $\$ 8.46$ & $\$ 10.19$ & $\$ 11.13$ & $\$ 12.06$ & $\$ 13.08$ & $\$ 13.89$ & $\$ 14.57$ & $\$ 15.21$ & $\$ 15.68$ & $\$ 15.89$ & $\$ 15.91$ & $\$ 15.86$ & $\$ 15.82$ \\
\hline$d 4 T$ & $\$ 5.02$ & $\$ 5.08$ & $\$ 2.43$ & $\$ 1.40$ & $\$ 1.23$ & $\$ 1.22$ & $\$ 1.23$ & $\$ 1.25$ & $\$ 1.31$ & $\$ 1.41$ & $\$ 1.54$ & $\$ 1.67$ & $\$ 1.76$ & $\$ 1.81$ \\
\hline $3 T C$ & $\$ 2.28$ & $\$ 2.54$ & $\$ 3.28$ & $\$ 3.32$ & $\$ 2.67$ & $\$ 1.88$ & $\$ 1.49$ & $\$ 1.49$ & $\$ 1.68$ & $\$ 1.90$ & $\$ 2.11$ & $\$ 2.27$ & $\$ 2.37$ & $\$ 2.42$ \\
\hline EFV & NR & TV & NR & $\$ 3.39$ & $\$ 4.01$ & $\$ 4.58$ & $\$ 4.93$ & 5.09 & $\$ 5.26$ & $\$ 5.49$ & $\$ 5.76$ & $\$ 5.92$ & $\$ 5.86$ & $\$ 5.56$ \\
\hline$L P V / r^{A}$ & $\$ 15.91$ & $\$ 17.85$ & $\$ 21.51$ & $\$ 23.51$ & $\$ 25.45$ & $\$ 27.58$ & $\$ 29.21$ & $\$ 30.32$ & $\$ 30.94$ & $\$ 30.75$ & $\$ 29.78$ & $\$ 28.71$ & $\$ 28.31$ & $\$ 28.8$ \\
\hline $\mathrm{LPV} / \mathrm{r}^{\mathrm{B}}$ & $\$ 15.91$ & $\$ 16.91$ & $\$ 14.11$ & $\$ 13.45$ & $\$ 14.50$ & $\$ 15.93$ & $\$ 16.87$ & $\$ 17.50$ & $\$ 18.41$ & $\$ 19.94$ & $\$ 22.04$ & $\$ 24.37$ & $\$ 26.58$ & $\$ 28.4$ \\
\hline$N V P^{A}$ & $\$ 4.42$ & $\$ 4.97$ & $\$ 5.74$ & $\$ 6.11$ & $\$ 6.39$ & $\$ 6.68$ & $\$ 6.91$ & $\$ 7.00$ & $\$ 6.84$ & $\$ 6.27$ & $\$ 5.33$ & $\$ 4.32$ & $\$ 3.55$ & $\$ 3.16$ \\
\hline$N V P^{B}$ & $\$ 3.77$ & $\$ 4.23$ & $\$ 5.09$ & $\$ 5.57$ & $\$ 6.03$ & $\$ 6.52$ & $\$ 6.87$ & $\$ 7.00$ & $\$ 6.84$ & $\$ 6.27$ & $\$ 5.33$ & $\$ 4.32$ & $\$ 3.55$ & $\$ 3.16$ \\
\hline$Z D V^{A}$ & $\$ 5.02$ & $\$ 5.64$ & $\$ 6.78$ & $\$ 7.25$ & $\$ 7.42$ & $\$ 7.58$ & $\$ 7.78$ & $\$ 8.02$ & $\$ 8.22$ & $\$ 8.23$ & $\$ 8.03$ & $\$ 7.73$ & $\$ 7.47$ & $\$ 7.34$ \\
\hline$Z D V^{B}$ & $\$ 4.19$ & $\$ 4.70$ & $\$ 5.66$ & $\$ 6.19$ & $\$ 6.70$ & $\$ 7.26$ & $\$ 7.69$ & $\$ 8.01$ & $\$ 8.22$ & $\$ 8.23$ & $\$ 8.03$ & $\$ 7.73$ & $\$ 7.47$ & $\$ 7.34$ \\
\hline ZDV/3TC & $\$ 4.19$ & $\$ 4.70$ & $\$ 5.66$ & $\$ 6.19$ & $\$ 6.70$ & $\$ 7.27$ & $\$ 7.72$ & $\$ 8.12$ & $\$ 8.50$ & $\$ 8.82$ & $\$ 9.01$ & $\$ 9.09$ & $\$ 9.12$ & $\$ 9.12$ \\
\hline ZDV/3TC/NVP & $\$ 5.86$ & $\$ 6.58$ & $\$ 7.93$ & $\$ 8.66$ & $\$ 9.38$ & $\$ 10.17$ & $\$ 10.79$ & $\$ 11.29$ & $\$ 11.71$ & $\$ 11.96$ & $\$ 11.96$ & $\$ 11.82$ & $\$ 11.67$ & $\$ 11.58$ \\
\hline $\mathrm{d} 4 \mathrm{~T} / 3 \mathrm{TC}$ & $\$ 2.51$ & $\$ 2.82$ & $\$ 3.40$ & $\$ 3.71$ & $\$ 4.02$ & $\$ 4.35$ & $\$ 4.61$ & $\$ 4.76$ & $\$ 4.82$ & $\$ 4.70$ & $\$ 4.43$ & $\$ 4.09$ & $\$ 3.83$ & $\$ 3.69$ \\
\hline $\mathrm{d} 4 \mathrm{~T} / 3 \mathrm{TC} / \mathrm{NVP}$ & $\$ 3.35$ & $\$ 3.76$ & $\$ 4.53$ & $\$ 4.95$ & $\$ 5.36$ & $\$ 5.81$ & $\$ 6.17$ & $\$ 6.46$ & $\$ 6.71$ & $\$ 6.86$ & $\$ 6.88$ & $\$ 6.82$ & $\$ 6.74$ & $\$ 6.70$ \\
\hline $\mathrm{ABC} / 3 \mathrm{TC}$ & $\$ 7.54$ & $\$ 8.46$ & $\$ 10.19$ & $\$ 11.13$ & $\$ 12.06$ & $\$ 13.08$ & $\$ 13.92$ & $\$ 14.69$ & $\$ 15.51$ & $\$ 16.30$ & $\$ 16.92$ & $\$ 17.34$ & $\$ 17.59$ & $\$ 17.69$ \\
\hline
\end{tabular}

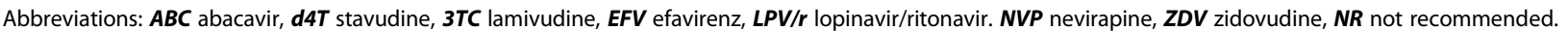
A. Patients are assumed to start the liquid formulation of the medication and then switch directly to pediatric or adult tablets when recommended (by weight). B. Patients are assumed to start pediatric tablet formulations of the medication at 0.5 years old (or at earliest recommended age) and then switch to adult tablets when recommended (by weight).

formulations of all drug components are used until 6 months of age, and then children switch to pediatric/adult tablets as recommended by weight-based dosing.

Scenario 3 (Available FDCs, Early Switch): Coformulations are available. Coformulated pediatric tablets, if they exist, are used from birth. If all drug components are not included in the coformulation, liquid formulations of the remaining drugs are used until 6 months of age, and then children switch to pediatric/adult tablets as recommended by weight-based dosing.

For example, South Africa currently has access to most pediatric liquid and tablet formulations, but co-formulations are not widely available $[17,18]$. Therefore, when compiling monthly regimen costs for South Africa, individual liquid or tablet doses must be used instead of the fixed dose combination pills (Scenarios 1 and 2). The above scenarios reflect only three possible assumptions regarding the settings for pediatric ART availability. Alternate scenarios can be analyzed with use of the online tool.

7. Comparison of derived to published costs. After completion of the six steps above, we compared our calculated monthly ART costs (by weight) to other published costs. The WHO has compiled a Global Price Reporting Mechanism (GPRM) database, which contains average yearly costs for both adult and pediatric ARVs, based on international transactions of HIV, tuberculosis and malaria medications purchased in resource-limited settings [36]. Costs for pediatric drug formulations in the GPRM database are shown only for children weighing $10 \mathrm{~kg}$. Here, we compare both pediatric and adult GPRM costs to the costs derived for the most relevant weight band in our analysis (pediatric: weight bands 6-9.9 kg and 10-13.9 kg adult: $35+\mathrm{kg})$.

\section{Results}

1. Weight-based doses for each antiretroviral drug (Table 1). Table 1 lists the recommended daily dose of each drug across all seven weight bands used in the WHO 2010 and 2013guidelines.

2. Assignment of unit costs for each antiretroviral drug (Table 2). Unit costs for each drug, using CHAI and MSF costs as an example, are shown in Table 2 [24,25].

3. Calculation of monthly costs for each medication and weight band (Table 3). With daily dosing 
Table 6 Monthly regimen costs: Six commonly used regimens

\begin{tabular}{|c|c|c|c|c|c|c|c|c|c|c|c|c|c|c|}
\hline \multirow[b]{2}{*}{ Regimen $^{A}$} & \multicolumn{14}{|c|}{ Age (years) } \\
\hline & 0.5 & 1 & 2 & 3 & 4 & 5 & 6 & 7 & 8 & 9 & 10 & 11 & 12 & 13 \\
\hline \multicolumn{15}{|c|}{$\mathrm{LPV} / \mathrm{R}+\mathrm{ZDV}+3 \mathrm{TC}$} \\
\hline Scenario 1 & $\$ 23.22$ & $\$ 26.03$ & $\$ 31.57$ & $\$ 34.08$ & $\$ 23.86$ & $\$ 25.07$ & $\$ 26.05$ & $\$ 27.00$ & $\$ 28.30$ & $\$ 30.07$ & $\$ 32.17$ & $\$ 34.36$ & $\$ 36.42$ & $\$ 38.21$ \\
\hline Scenario 2 & $\$ 22.38$ & $\$ 24.15$ & $\$ 23.05$ & $\$ 22.96$ & $\$ 23.86$ & $\$ 25.07$ & $\$ 26.05$ & $\$ 27.00$ & $\$ 28.30$ & $\$ 30.07$ & $\$ 32.17$ & $\$ 34.36$ & $\$ 36.42$ & $\$ 38.21$ \\
\hline Scenario 3 & $\$ 20.10$ & $\$ 21.61$ & $\$ 19.77$ & $\$ 19.64$ & $\$ 21.20$ & $\$ 23.20$ & $\$ 24.59$ & $\$ 25.61$ & $\$ 26.91$ & $\$ 28.76$ & $\$ 31.04$ & $\$ 33.46$ & $\$ 35.69$ & $\$ 37.58$ \\
\hline \multicolumn{15}{|c|}{$L P V / R+A B C+3 T C$} \\
\hline Scenario 1 & $\$ 31.89$ & $\$ 35.65$ & $\$ 44.53$ & $\$ 47.46$ & $\$ 29.22$ & $\$ 30.89$ & $\$ 32.25$ & $\$ 33.56$ & $\$ 35.29$ & $\$ 37.52$ & $\$ 40.03$ & $\$ 42.55$ & $\$ 44.81$ & $\$ 46.70$ \\
\hline Scenario 2 & $\$ 25.73$ & $\$ 27.91$ & $\$ 27.57$ & $\$ 27.91$ & $\$ 29.22$ & $\$ 30.89$ & $\$ 32.25$ & $\$ 33.56$ & $\$ 35.29$ & $\$ 37.52$ & $\$ 40.03$ & $\$ 42.55$ & $\$ 44.81$ & $\$ 46.70$ \\
\hline Scenario 3 & $\$ 23.45$ & $\$ 25.36$ & $\$ 24.30$ & $\$ 24.59$ & $\$ 26.56$ & $\$ 29.01$ & $\$ 30.79$ & $\$ 32.18$ & $\$ 33.92$ & $\$ 36.23$ & $\$ 38.95$ & $\$ 41.71$ & $\$ 44.16$ & $\$ 46.15$ \\
\hline \multicolumn{15}{|c|}{$\mathrm{LPV} / \mathrm{R}+\mathrm{D} 4 \mathrm{~T}+3 \mathrm{TC}$} \\
\hline Scenario 1 & $\$ 23.22$ & $\$ 25.48$ & $\$ 27.22$ & $\$ 28.23$ & $\$ 18.40$ & $\$ 19.03$ & $\$ 19.58$ & $\$ 20.24$ & $\$ 21.40$ & $\$ 23.25$ & $\$ 25.68$ & $\$ 28.31$ & $\$ 30.71$ & $\$ 32.68$ \\
\hline Scenario 2 & $\$ 23.21$ & $\$ 24.53$ & $\$ 19.81$ & $\$ 18.17$ & $\$ 18.40$ & $\$ 19.03$ & $\$ 19.58$ & $\$ 20.24$ & $\$ 21.40$ & $\$ 23.25$ & $\$ 25.68$ & $\$ 28.31$ & $\$ 30.71$ & $\$ 32.68$ \\
\hline Scenario 3 & $\$ 18.42$ & $\$ 19.73$ & $\$ 17.50$ & $\$ 17.16$ & $\$ 18.52$ & $\$ 20.29$ & $\$ 21.47$ & $\$ 22.26$ & $\$ 23.22$ & $\$ 24.64$ & $\$ 26.46$ & $\$ 28.46$ & $\$ 30.40$ & $\$ 32.15$ \\
\hline \multicolumn{15}{|c|}{ NVP OR EFV + ZDV $+3 T C^{B}$} \\
\hline Scenario 1 & $\$ 11.72$ & $\$ 13.15$ & $\$ 15.80$ & $\$ 13.96$ & $\$ 13.37$ & $\$ 13.72$ & $\$ 14.11$ & $\$ 14.59$ & $\$ 15.15$ & $\$ 15.63$ & $\$ 15.89$ & $\$ 15.92$ & $\$ 15.71$ & $\$ 15.32$ \\
\hline Scenario 2 & $\$ 10.24$ & $\$ 11.47$ & $\$ 14.04$ & $\$ 12.89$ & $\$ 13.37$ & $\$ 13.72$ & $\$ 14.11$ & $\$ 14.59$ & $\$ 15.15$ & $\$ 15.63$ & $\$ 15.89$ & $\$ 15.92$ & $\$ 15.71$ & $\$ 15.32$ \\
\hline Scenario 3 & $\$ 5.86$ & $\$ 6.58$ & $\$ 7.93$ & $\$ 9.57$ & $\$ 10.71$ & $\$ 11.85$ & $\$ 12.65$ & $\$ 13.21$ & $\$ 13.76$ & $\$ 14.31$ & $\$ 14.77$ & $\$ 15.01$ & $\$ 14.98$ & $\$ 14.68$ \\
\hline \multicolumn{15}{|c|}{ NVP OR EFV $+A B C+3 T C^{B}$} \\
\hline Scenario 1 & $\$ 20.40$ & $\$ 22.77$ & $\$ 28.76$ & $\$ 27.34$ & $\$ 18.73$ & $\$ 19.54$ & $\$ 20.31$ & $\$ 21.16$ & $\$ 22.14$ & $\$ 23.07$ & $\$ 23.75$ & $\$ 24.10$ & $\$ 24.09$ & $\$ 23.80$ \\
\hline Scenario 2 & $\$ 13.59$ & $\$ 15.23$ & $\$ 18.56$ & $\$ 17.84$ & $\$ 18.73$ & $\$ 19.54$ & $\$ 20.31$ & $\$ 21.16$ & $\$ 22.14$ & $\$ 23.07$ & $\$ 23.75$ & $\$ 24.10$ & $\$ 24.09$ & $\$ 23.80$ \\
\hline Scenario 3 & $\$ 11.31$ & $\$ 12.68$ & $\$ 15.28$ & $\$ 14.52$ & $\$ 16.06$ & $\$ 17.66$ & $\$ 18.85$ & $\$ 19.78$ & $\$ 20.76$ & $\$ 21.79$ & $\$ 22.68$ & $\$ 23.26$ & $\$ 23.45$ & $\$ 23.25$ \\
\hline \multicolumn{15}{|c|}{ NVP OR EFV + D4T +3TC } \\
\hline Scenario 1 & $\$ 11.72$ & $\$ 12.60$ & $\$ 11.45$ & $\$ 8.11$ & $\$ 7.90$ & $\$ 7.68$ & $\$ 7.64$ & $\$ 7.84$ & $\$ 8.24$ & $\$ 8.81$ & $\$ 9.41$ & $\$ 9.86$ & $\$ 10.00$ & $\$ 9.79$ \\
\hline Scenario 2 & $\$ 11.07$ & $\$ 11.85$ & $\$ 10.80$ & $\$ 8.11$ & $\$ 7.90$ & $\$ 7.68$ & $\$ 7.64$ & $\$ 7.84$ & $\$ 8.24$ & $\$ 8.81$ & $\$ 9.41$ & $\$ 9.86$ & $\$ 10.00$ & $\$ 9.79$ \\
\hline Scenario 3 & $\$ 3.35$ & $\$ 3.76$ & $\$ 4.53$ & $\$ 7.10$ & $\$ 8.03$ & $\$ 8.94$ & $\$ 9.53$ & $\$ 9.85$ & $\$ 10.07$ & $\$ 10.20$ & $\$ 10.18$ & $\$ 10.01$ & $\$ 9.69$ & $\$ 9.25$ \\
\hline
\end{tabular}

Abbreviations: $\boldsymbol{A B C}$ abacavir, $\boldsymbol{d 4 T}$ stavudine, 3TC lamivudine, $\boldsymbol{E F V}$ efavirenz, $\mathbf{L P V / r}$ lopinavir/ritonavir, $\boldsymbol{N} \boldsymbol{V} \boldsymbol{P}$ nevirapine, $\boldsymbol{Z D V}$ zidovudine,

A. ARV availability scenarios (see also Methods):

Scenario 1 (No FDCs, Late Switch): Coformulations are not available. Liquid formulations of all drug components are used until 4 years of age, and then children switch to pediatric/adult tablets as recommended by weight-based dosing.

Scenario 2 (No FDCs, Early Switch): Coformulations are not available. Liquid formulations of all drug components are used until 6 months of age, and then children switch to pediatric/adult tablets as recommended by weight-based dosing.

Scenario 3 (Available FDCs, Early Switch): Coformulations are available. Coformulated pediatric tablets, if they exist, are used from birth. If all drug components are not included in the coformulation, liquid formulations of the remaining drugs are used until 6 months of age, and then children switch to pediatric/adult tablets as recommended by weight-based dosing.

B. Patients on the non-nucleoside reverse transcriptase inhibitor (NNRTI)-based regimens are assumed to receive NVP until age 3, then EFV at age 3 and after because EFV is not yet approved for children less than 3 years of age or $10 \mathrm{~kg}$ of weight.

recommendations and unit costs by drug, we then calculated monthly costs for each drug, stratified by weight band. Monthly costs for each drug formulation are shown in Table 3 for each WHO weight band where that drug formulation is recommended.

4. Probability of being in each WHO weight band by age (Table 4). The probability of being in each WHO weight band by current age and gender was calculated as described in the Methods. Results are shown in Table 4 assuming an equal distribution of males and females.

Sensitivity analyses on weight distributions demonstrated that monthly drug cost estimates were fairly robust to changes in assumptions regarding the weight distribution for HIV-infected children (z-scores). Assuming no change in weight distribution between HIV-infected children and the general population $(\mathrm{z}$-score $=0$ ), monthly drug costs by age changed on average by $9.7 \%$. Monthly drug costs changed substantially from our original estimates $(>10 \%)$ only when we assumed much lower weights among HIV-infected children ( $z$-score $\leq-3$ ). With improvements in early infant diagnosis and access to antiretroviral therapy (ART), we anticipate that the growth distribution for HIV-infected children will shift toward the WHO growth curves for the general population, and thus drug costs will remain similar to 
those calculated in this manuscript. Sensitivity analyses on the coefficient of variation of the weight distribution among HIV-infected children $\left(\mathrm{S}_{\mathrm{HIV}}\right)$ also demonstrated minimal change in monthly drug costs estimates. First, assuming that $\mathrm{S}_{\mathrm{HIV}}$ was equal to half the coefficient of variation of the general population, we found that monthly drug costs changed by $4.2 \%$, on average. Second, assuming $\mathrm{S}_{\mathrm{HIV}}$ was double the coefficient of variation of the general population, we found that monthly drug costs changed on average by $6.4 \%$.

5. Calculation of monthly costs for each medication by age (Table 5). Using the probabilities of being in each weight band (Table 4) and the monthly costs for each medication by weight band (Table 3), we calculated the monthly cost for each medication by age (Table 5).

6. Calculation of monthly costs for complete medication regimens (Table 6). Monthly costs for complete regimens are shown in Table 6, for a variety of

Table 7 Comparison of pediatric formulation derived costs to the WHO Global Price Reporting Mechanism (GPRM) database

\begin{tabular}{|c|c|c|c|}
\hline Medication (strength) & $\begin{array}{l}\text { Monthly } \\
\text { costs for } \\
6-9.9 \text { kg } \\
\text { (Table 3) }\end{array}$ & $\begin{array}{c}\text { Monthly } \\
\text { costs for } \\
10-13.9 \text { kg } \\
\text { (Table 3) }\end{array}$ & $\begin{array}{c}\text { Monthly } \\
\text { costs }^{A} \\
\text { From } \\
\text { GPRM }\end{array}$ \\
\hline ABC (20 mg/ml) & $\$ 14.59$ & $\$ 21.89$ & $\$ 15.84$ \\
\hline ABC (60 mg) & $\$ 8.21$ & $\$ 10.94$ & $\$ 12.36$ \\
\hline $\mathrm{d} 4 \mathrm{~T}(1 \mathrm{mg} / \mathrm{ml})$ & $\$ 5.47$ & NR & $\$ 4.56$ \\
\hline $\mathrm{d} 4 \mathrm{~T}(15 \mathrm{mg})$ & NR & $\$ 1.22$ & $\$ 1.44$ \\
\hline 3TC (10 mg/ml) & $\$ 2.43$ & $\$ 3.65$ & $\$ 2.06$ \\
\hline LPV/r (80/20 mg/ml) & $\$ 17.33$ & $\$ 23.10$ & $\$ 11.81$ \\
\hline LPV/r (100/25 mg) & NR & $\$ 12.77$ & $\$ 11.20$ \\
\hline NVP (10 mg/ml) & $\$ 4.86$ & $\$ 6.08$ & $\$ 4.81$ \\
\hline NVP (50 mg) & $\$ 4.10$ & $\$ 5.47$ & N/A \\
\hline ZDV (10 mg/ml) & $\$ 5.47$ & $\$ 7.30$ & $\$ 4.82$ \\
\hline ZDV (60 mg) & $\$ 4.56$ & $\$ 6.08$ & N/A \\
\hline ZDV/3TC (60 mg/30 mg) & $\$ 4.56$ & $\$ 6.08$ & $\$ 5.60$ \\
\hline ZDV/3TC/NVP (60 mg/30 mg/50 mg) & $\$ 6.38$ & $\$ 8.51$ & $\$ 8.28$ \\
\hline $\mathrm{d} 4 \mathrm{~T} / 3 \mathrm{TC}(6 \mathrm{mg} / 30 \mathrm{mg})$ & $\$ 2.74$ & $\$ 3.65$ & $\$ 3.79$ \\
\hline $\mathrm{d} 4 \mathrm{~T} / 3 \mathrm{TC} / \mathrm{NVP}(6 \mathrm{mg} / 30 \mathrm{mg} / 50 \mathrm{mg})$ & $\$ 3.65$ & $\$ 4.86$ & $\$ 4.66$ \\
\hline ABC/3TC (60 mg/30 mg) & $\$ 8.21$ & $\$ 10.94$ & $\$ 13.96$ \\
\hline
\end{tabular}

Abbreviations: $\boldsymbol{A B C}$ abacavir, $\boldsymbol{d} \mathbf{4 T}$ stavudine, 3TC lamivudine, EFV efavirenz, $\boldsymbol{L P V / r}$ lopinavir/ritonavir, $\boldsymbol{N} \boldsymbol{P}$ nevirapine, $\boldsymbol{Z D V}$ zidovudine, $\boldsymbol{m g}$ milligrams, $\boldsymbol{m l}$ milliliter, $\boldsymbol{N} \boldsymbol{R}$ not recommended, $\boldsymbol{N} / \boldsymbol{A}$ not applicable (no cost estimate was available from the GPRM for this formulation).

A. Pediatric formulations in the WHO GPRM are based on costs for a $10 \mathrm{~kg}$ child. We have shown our calculations from Table 3 for weight bands $6-9.9 \mathrm{~kg}$ and $10-13.0 \mathrm{~kg}$ as a comparison. regimens and formulations to reflect the range of settings described in the Methods. As seen in the Table, monthly regimen costs do not increase monotonically as a child grows. This is due to the switch from more expensive liquid and pediatric tablet formulations to adult tablet doses. In addition, the switch from NVP to EFV at age three also increases overall monthly regimen costs.

7. Comparison of derived to published costs. Compared to the pediatric drug costs reported in the WHO GPRM database (based on children weighing $10 \mathrm{~kg}$ ), the costs derived in our analysis for children in weight bands $6-9.9 \mathrm{~kg}$ and $10-13.9 \mathrm{~kg}$ were fairly comparable or slightly higher for most formulations (Table 7). One exception of note is our estimate of $\mathrm{LPV} / \mathrm{r}$ syrup costs $(80 / 20 \mathrm{mg} / \mathrm{ml})$. Using our methodology, the cost range for this formulation in weight bands $6-9.9 \mathrm{~kg}$ and $10-13.9 \mathrm{~kg}$ was almost double that reported in the GPRM (\$17.33-\$23.10 versus \$11.81). All costs estimates from our analysis for the $35+\mathrm{kg}$ weight band were also comparable or slightly higher than the adult formulation costs reported in the WHO GPRM (Table 8).

\section{Discussion}

In this paper, we have provided a standardized methodology for estimating monthly pediatric ARV costs that could allow for greater comparability between future

Table 8 Comparison of adult formulation derived costs to the WHO Global Price Reporting Mechanism (GPRM) database

\begin{tabular}{lcc}
\hline Medication (strength) & $\begin{array}{c}\text { Monthly costs for } \\
\text { 35 + kg (from Table 3) }\end{array}$ & $\begin{array}{c}\text { Monthly costs } \\
\text { from GPRM }\end{array}$ \\
\hline ABC (300 mg) & $\$ 15.81$ & $\$ 13.39$ \\
d4T (30 mg) & $\$ 1.82$ & $\$ 1.52$ \\
$3 T C(150 \mathrm{mg})$ & $\$ 2.43$ & $\$ 2.36$ \\
EFV (600 mg) & $\$ 4.56$ & $\$ 3.86$ \\
LPV/r (200/50 mg) & $\$ 31.62$ & $\$ 29.47$ \\
NVP (200 mg) & $\$ 3.04$ & $\$ 2.47$ \\
ZDV (300 mg) & $\$ 7.30$ & $\$ 6.98$ \\
ZDV/3TC (300 mg/150 mg) & $\$ 9.12$ & $\$ 7.86$ \\
ZDV/3TC/NVP (300 mg/150 & $\$ 11.55$ & $\$ 9.89$ \\
mg/200 mg) & & $\$ 2.99$ \\
d4T/3TC (30 mg/150 mg) & $\$ 3.65$ & $\$ 4.76$ \\
d4T/3TC/NVP (30 mg/150 & $\$ 6.69$ & $\$ 22.56$ \\
mg/200 mg) & & \\
ABC/3TC (600 mg/300 mg) & $\$ 17.72-\$ 32.53$ &
\end{tabular}

Abbreviations: ABC abacavir, d4T stavudine, 3TC lamivudine, EFV efavirenz, LPV/r lopinavir/ritonavir, NVP nevirapine, $\boldsymbol{Z} \boldsymbol{D} \boldsymbol{V}$ zidovudine, $\boldsymbol{m} \boldsymbol{g}$ milligrams, $\boldsymbol{m} \boldsymbol{I}$ milliliter, $\boldsymbol{N} \boldsymbol{R}$ not recommended, $\boldsymbol{N} / \boldsymbol{A}$ not applicable (no cost estimate was available from the GPRM for this formulation). 
analyses of cost-effectiveness. Our approach incorporates changing dosing requirements as children grow, and accounts for a range of scenarios for the availability of pediatric ARV formulations in different countries and settings. To date, there have been no other published procedures for estimating pediatric ART costs by age and by drug regimen. Meyer-Rath et al. focused their analysis on calculating the average cost of HIV treatment care across at two pediatric care sites in South Africa [23]. They further estimated that approximately $\$ 25 /$ month (or $40 \%$ of the total per-patient cost over the two years following treatment initiation) pertained to pediatric ART costs. Recommended pediatric regimens at these sites included $\mathrm{d} 4 \mathrm{~T} / 3 \mathrm{TC} / \mathrm{LPV} / \mathrm{r}$ for children less than 3 years of age, and $\mathrm{d} 4 \mathrm{~T} / 3 \mathrm{TC} / \mathrm{EFV}$ for children greater than 3 years of age, with a median age of 4-6 years at initiation across the two sites. In our analysis, we found similar monthly costs for $\mathrm{d} 4 \mathrm{~T} / 3 \mathrm{TC} / \mathrm{LPV} / \mathrm{r}$, which ranged from $\$ 18.40$ - $\$ 21.47$ for children ages 4-6 years old, depending on formulation assumptions. However, our monthly cost estimates for d4T/3TC/EFV (\$7.64\$9.53) for children ages 4-6 years old, were significantly lower (Table 6). This discrepancy could be due to additional programmatic costs (cold chain storage, shipping costs, etc.) that may have also been included in the pediatric ART costs in the Meyer-Rath estimation.

In addition, the WHO has compiled average monthly costs for several pediatric and adult drug formulations in their GPRM database based on records of international transactions of HIV, tuberculosis and malaria products purchased in low- and middle-income countries [36], focused on $10-\mathrm{kg}$ children. Here, our monthly drug costs for children in weight bands $6-9.9 \mathrm{~kg}$ and $10-13.9 \mathrm{~kg}$ were fairly comparable or slightly higher for most formulations (Table 7). We did find, though, that our estimate of the liquid $\mathrm{LPV} / \mathrm{r}$ formulation $(80 / 20 \mathrm{mg} / \mathrm{ml})$, which ranged from $\$ 17.33-\$ 23.10$ was almost double the cost reported in the WHO GPRM Database (\$11.81). This discrepancy is likely due to the inherent differences in a ceiling price list (used in our analysis for unit cost derivation) and the actual transaction costs found in the GPRM. For example, despite the high cost of liquid $\mathrm{LPV} / \mathrm{r}(80 / 20 \mathrm{mg} / \mathrm{ml})$, many countries and programs may have been able to negotiate its purchase at a lower cost than listed in the CHAI price list because of its key role in pediatric HIV treatment. In addition, the GPRM database shows that prices for LPV/r have fallen substantially over the past five years, from $\$ 16.11$ to $\$ 11.81$ per month, demonstrating the rapidly changing economic market for this drug. Our costing methodology described in this paper provides a more detailed and transparent estimation of ART costs over several ages, which will be useful in formulating pediatric ART recommendations in the future.
Our costing procedure has several limitations. First, we describe a step-by-step approach for calculating drugrelated pediatric ART costs. These costs do not take into consideration equipment, personnel, overhead, shipping or opportunity costs that may also be involved in the delivery of ART to pediatric patients. We have also excluded the costs of establishing and maintaining a cold chain store needed for drugs that require refrigeration. The costs of these components are infrequently reported, but will likely inflate LPV/r liquid formulation costs by $5-50 \%$ depending on program level cold chain storage capabilities. Although we have chosen to exclude these variable costs from our analysis, the investments needed to establish a cold chain facility may be available at the program level and will be important considerations for program planners to include. In addition, because entire bottles of liquid formulation must be dispensed monthly, often exceeding the total needed quantity, there will likely be some wastage associated with the distribution of liquid drugs. Our current methodology excludes wastage costs, but these will need to be considered by program planners as well. Our costs estimates, however, will allow providers to incorporate drug-related pediatric ART costs into their existing budget and thus permit this methodology to apply to a variety of clinical settings. And finally, pediatric ART costs will likely change over time with the addition of new formulations of existing drugs or the development of new pediatric and adult medications. For example, LPV/r sprinkles and modifiable-dose ARV sachets are currently under development [37]. These formulations may improve tolerability and dosing flexibility, and also may also remove storage requirements that are a significant barrier to scale up of LPV/r use. A cost estimate has not yet been released for these formulations, but will be necessary to determine their cost effectiveness in the context of other available ARV options [37]. The methodology described here can be used as a framework for these and other drug developments in the future.

\section{Conclusions}

The number of children living with HIV is growing each year, and will likely continue to grow until efforts to prevent perinatal HIV infection reach target goals [38]. Antiretroviral therapy has been shown to drastically reduce morbidity and mortality in children with HIV, yet questions about when to start treatment and what treatment to start remain key issues for policy makers [2,39]. In order to thoroughly examine these questions, one must be able to accurately assess the costs of pediatric antiretroviral therapy. We hope that the methodology outlined in this paper can be used as a standardized approach for budget administrators and cost-effectiveness analysts, who seek to increase pediatric ART availability in a constrained budget environment and that our detailed 
procedure will allow for more accurate comparison of pediatric drug costing across methodologies and evaluations. This costing procedure can be modified to reflect ARV prices and available formulations that are most representative for a range of programs and settings, and thus can aid budget analysts in developing more cost-effective recommendations for pediatric ART.

\section{Additional file}

Additional file 1: Calculate monthly ART costs by regimen and age.

\section{Abbreviations}

3TC: Lamivudine; ABC: Abacavir; ART: Antiretroviral therapy; ARV: Antiretroviral; CDC: Center for Disease Control; CHAl: Clinton Health Access Initiative; D4T: Stauvudine; EFV: Efavirenz; FDC: Fixed dose combination; GPRM: Global Price Reporting Mechanism; LPV/r: Lopinavir/ ritonavir; MSF: Mèdecins Sans Frontières; NVP: Nevirapine; PEPFAR: The U.S. President's Emergency Plan for AIDS Relief; WHO: World Health Organization; ZDV: Zidovudine.

\section{Competing interests}

Dr Holmes was employed by Gilead Sciences from July 2006-January 2008 and was a stockholder during that time. All other authors declare they have no competing interests.

\section{Authors' contributions}

$A C$ and $K D$ developed the costing methodology and drafted the manuscript. SR developed the methodology for weight-to-age standards. SE, MP, CH and SR provided critical support to the costing procedure and revising the manuscript. All authors read and approved the final manuscript.

\section{Acknowledgements}

The authors gratefully acknowledge the assistance of Andrew King and Zach Ward for calculations of weight-to-age distributions and of Dr. Lulu Muhe, World Health Organization, for comments on the analysis. We also thank the entire Cost-effectiveness of Preventing AIDS Complications (CEPAC)-International investigator team.

This work was supported by the National Institutes of Health, including the National Institute of Allergy and Infectious Disease (NIAID: K01 AI078754 (ALC); R01 AI058736 (KD) and the IMPAACT network (NIAID and the Eunice Kennedy Shriver National Institute of Child Health and Human Development (NICHD) through a subaward from Johns Hopkins University: UM Al068632 (KD); and the World Health Organization (AC, MP, SE, KD). Overall support for IMPAACT was provided by the National Institute of Allergy and Infectious Diseases (NIAID) [U01 Al068632], the Eunice Kennedy Shriver National Institute of Child Health and Human Development (NICHD), and the National Institute of Mental Health (NIMH) [Al068632]. The content is solely the responsibility of the authors and does not necessarily represent the official views of the $\mathrm{NIH}$. This work was supported by the Statistical and Data Analysis Center at Harvard School of Public Health, under the National Institute of Allergy and Infectious Diseases cooperative agreement \#5 U01 Al41110 with the Pediatric AIDS Clinical Trials Group (PACTG) and \#1 U01 Al068616 with the IMPAACT Group. Support of the sites was provided by the National Institute of Allergy and Infectious Diseases (NIAID) and the NICHD International and Domestic Pediatric and Maternal HIV Clinical Trials Network funded by NICHD (contract number N01-DK-9-001/HHSN267200800001C).

\section{Author details}

${ }^{1}$ Medical Practice Evaluation Center, Divisions of General Medicine, Massachusetts General Hospital, Boston, MA, USA. ²Department of Pediatrics, New York University School of Medicine, New York, NY, USA. ${ }^{3}$ Clinton Health Access Initiative, Boston, MA, USA. ${ }^{4}$ Clinical Trial Unit Medical Research Council, London, UK. ${ }^{5}$ Center for Infectious Disease Research in Zambia (CIDRZ), Lusaka, Zambia. ${ }^{6}$ Center for Health Decision Science, Harvard School of Public Health, Boston, MA, USA. ${ }^{7}$ Medical Practice Evaluation Center,
Divisions of General Medicine and Infectious Disease, Massachusetts General Hospital, Boston, MA, USA.

Received: 8 July 2013 Accepted: 2 April 2014

Published: 2 May 2014

\section{References}

1. World Health Organization: Progress Report 2011: Global HIV/AIDS response: epidemic update and health sector progress towards universal access. In [http://www.unaids.org/en/media/unaids/contentassets/ documents/epidemiology/2012/gr2012/20121120_UNAIDS_Global_Report_ 2012_with_annexes_en.pdf] Accessed October 16, 2013.

2. Violari A, Cotton MF, Gibb DM, Babiker AG, Steyn J, Madhi SA, Jean-Philippe P, McIntyre JA: Early antiretroviral therapy and mortality among HIV-infected infants. N Engl J Med 2008, 359(21):2233-2244.

3. UNAIDS: Report on the Global AIDS Epidemic. In [http://www.unaids.org/ en/media/unaids/contentassets/documents/epidemiology/2012/gr2012/

20121120_UNAIDS_Global_Report_2012_en.pdf] Accessed October 7, 2013.

4. The Henry J. Kaiser Family Foundation: U.S. Global Health Policy. In [http:// www.kff.org/globalhealth/upload/8002-04.pdf] Accessed October 25, 2012.

5. Meyer-Rath G, Violari A, Cotton M, Ndibongo B, Brenna A, Long L, Panchia R, Coovadia A, Gibb DM, Rosen S: THLBB103: The Cost of Early vs. Deferred Paediatric Antiretroviral Treatment in South Africa - a Comparative Economic Analysis of the First Year of the CHER Trial. In International AIDS society: 2010. Vienna, Austria; 2010.

6. Schneider K, Puthanakit T, Kerr S, Law MG, Cooper DA, Donovan B, Phanuphak N, Sirisanthana V, Ananworanich J, Ohata J, Wilson DP: Economic evaluation of monitoring virologic responses to antiretroviral therapy in HIV-infected children in resource-limited settings. AIDS 2011, 25(9):1143-1151.

7. World Health Organization: Antiretroviral Therapy for HIV Infection in Infants and Children: Recommendations for a Public Health Approach. In [http://www.who.int/hiv/pub/paediatric/infants2010/en/index.html] Accessed October 18, 2013.

8. Ciaranello A, Babiker A, Doherty K, Essajee K, Freedberg K, Gibb D, Harrison L, Hou T, Lindsey J, Losina E, Muhe L, Palumbo P, Penazzato M, Walensky $R$, Weinstein MC: First-line ART regimens for HIV-infected children: A model-based cost-effectiveness analysis. In World Health Organization Maternal and Child Health Guidelines Development Group Meeting: December 11-13, 2012; Geneva, Switzerland; 2012.

9. Palumbo P, Lindsey JC, Hughes MD, Cotton MF, Bobat R, Meyers T, Bwakura-Dangarembizi M, Chi BH, Musoke P, Kamthunzi P, Schimana W, Purdue L, Eshleman SH, Abrams EJ, Millar L, Petzold E, Mofenson LM, Jean-Philippe $P$, Violari A: Antiretroviral treatment for children with peripartum nevirapine exposure. N Engl J Med 2010, 363(16):1510-1520.

10. Violari A, Lindsey JC, Hughes MD, Mujuru HA, Barlow-Mosha L, Kamthunzi P, Chi BH, Cotton MF, Moultrie H, Khadse S, Schimana W, Bobat R, Purdue L, Eshleman SH, Abrams EJ, Millar L, Petzold E, Mofenson LM, Jean-Philippe P, Palumbo P: Nevirapine versus ritonavir-boosted lopinavir for HIV-infected children. N Engl J Med 2012, 366(25):2380-2389.

11. Anti-Retroviral Research for Watoto: ARROW Trial. In [http://www.arrowtrial. org/default.asp] Accessed November 1, 2013.

12. Paediatric European Network for Treatment of AIDS (PENTA): Comparison of dual nucleoside-analogue reverse-transcriptase inhibitor regimens with and without nelfinavir in children with HIV-1 who have not previously been treated: the PENTA 5 randomised trial. Lancet 2002, 359(9308):733-740.

13. O'Brien DP, Sauvageot D, Zachariah $R$, Humblet $P$ : In resource-limited settings good early outcomes can be achieved in children using adult fixed-dose combination antiretroviral therapy. AIDS 2006, 20(15):1955-1960.

14. Vanprapar N, Cressey TR, Chokephaibulkit K, Muresan P, Plipat N, Sirisanthana V, Prasitsuebsai W, Hongsiriwan S, Chotpitayasunondh T, Eksaengsri A, Toye M, Smith ME, McIntosh K, Capparelli E, Yogev R, IMPAACT P1056 Team: A chewable pediatric fixed-dose combination tablet of stavudine, lamivudine, and nevirapine: pharmacokinetics and safety compared with the individual liquid formulations in human immunodeficiency virus-infected children in Thailand. Pediatr Infect Dis $J$ 2010, 29(10):940-944.

15. Chokephaibulkit K, Cressey TR, Capparelli E, Sirisanthana V, Muresan P, Hongsiriwon S, Ngampiyaskul C, Limwongse C, Wittawatmongkol O, Aurpibul L, Kabat B, Toye M, Smith ME, Eksaengsri A, McIntosh K, Yogev R, 
IMPAACT P1069 Team: Pharmacokinetics and safety of a new paediatric fixed-dose combination of zidovudine/lamivudine/nevirapine in HIVinfected children. Antivir Ther 2011, 16(8):1287-1295.

16. WHO Paediatric Working Group: Interagency Task Team on Prevention and Treatment of HIV Infection in Pregnant Women, Mothers and Their Children: Developing an Optimized List of Paediatric ARV Formulations. Geneva, Switzerland: World Health Organization; 2011.

17. South African National Department of Health, Southern African HIV Clinicians Society: Antiretroviral drug dosing chart for children. In [http:// www.sahivsoc.org/upload/documents/2012\%20ARV\%20Dosing\%20Chart\% 20for\%20Children\%20and\%20Adolescents.pdf] Accessed April 10, 2013.

18. Department of Health Republic of South Africa: The South African Antiretroviral Treatment Guidelines. In [http://www.uj.ac.za/EN/ CorporateServices/ioha/Documentation/Documents/ART\%20Guideline.pdf] Accessed April 10, 2013.

19. Phelps BR, Rakhmanina N: Antiretroviral drugs in pediatric HIV-infected patients: pharmacokinetic and practical challenges. Paediatr Drugs 2011, 13(3):175-192

20. TREAT Asia Pediatric HIV Observational Database (TApHOD), International Epidemiologic Databases to Evaluate AIDS (leDEA) Southern Africa Paediatric Group: A biregional survey and review of first-line treatment failure and second-line paediatric antiretroviral access and use in Asia and southern Africa. J Int AIDS Soc 2011, 14:7.

21. Panel on Antiretroviral Therapy and Medication of HIV-Infected Children: Guidelines for the use of Antiretroviral Agents in Pediatric HIV Infection. Department of Health and Human Services. In [http://aidsinfo.nih.gov/ contentfiles/lvguidelines/pediatricguidelines.pdf] Accessed September 2, 2013.

22. Menzies NA, Berruti AA, Berzon R, Filler S, Ferris R, Ellerbrock TV, Blandford $\mathrm{JM}$ : The cost of providing comprehensive HIV treatment in PEPFARsupported programs. AIDS 2011, 25(14):1753-1760.

23. Meyer-Rath G, Brennan A, Long L, Ndibongo B, Technau K, Moultrie H, Fairlie L, Coovadia A, Rosen S: Cost and outcomes of paediatric antiretroviral treatment in South Africa. AIDS 2013, 27(2):243-250.

24. Clinton Health Access Initiative: Antiretroviral (ARV) Ceiling Price List. In [http://d2pd3b5abq75bb.cloudfront.net/2012/07/12/15/03/07/163/ CHAI_ARV_Ceiling_Price_List_May_2012.pdf] Accessed October 14, 2013

25. Médecins Sans Frontières: Untangling the web of Antiretroviral Price Reductions: 15th Edition. In [http://aids2012.msf.org/wp-content/uploads/ 2012/07/MSF_Access_UTW_15th_Edition_2012_webres.pdf] Accessed April 10, 2013.

26. Heath-e: ARV Tenders Mean More can now Access Treatment. In [http:// www.health-e.org.za/2010/12/15/arv-tenders-mean-more-can-now-accesstreatment/] Accessed April 10, 2013

27. United Nations: PAHO lauds 10 Latin American countries for negotiating discounts for HIV drugs. In [http://www.un.org/apps/news/story.asp? NewsID=7416\&Cr=hiv\&Cr1=aids] Accessed May 6, 2014

28. World Health Organization: Consolidated Guidelines on the use of Antiretrovirals for the Treatment and Prevention of HIV Infection. In [http://www.who.int/hiv/pub/guidelines/arv2013/download/en/index.html] Accessed October 20, 2013.

29. President's Emergency Plan for AIDS Relief (PEPFAR): Approved and Tentatively Approved Antiretrovirals in Association with the President's Emergency Plan. In [http://www.fda.gov/InternationalPrograms/ FDABeyondOurBordersForeignOffices/AsiaandAfrica/ucm119231.htm] Accessed February 7, 2013

30. World Health Organization Multicentre Growth Reference Study Group: WHO Child Growth Standards: Length/Height-for-age, Weight-for-age, Weight-for-Length, Weight-for-Height and Body Mass Index-for-age: Methods and Development. In [http://www.who.int/childgrowth/ standards/technical_report/en/index.html] Accessed October 19, 2013.

31. Center for Disease Control and Prevention (CDC): Data Table of Weight-for-age Charts. In [http://www.cdc.gov/growthcharts/html_charts/ wtage.htm] Accessed December 21, 2012.

32. Cole TJ: The LMS method for constructing normalized growth standards. Eur J Clin Nutr 1990, 44(1):45-60.

33. Ciaranello A, Chang Y, Margulis A, Bernstein A, Bassett IV, Losina E, Walensky RP: Effectiveness of pediatric ART in resource-limited settings: a systematic review and meta-analysis. Clin Infect Dis 2009, 49(12):1915-1927.

34. Center for Disease Control and Prevention (CDC): Percentile Data Files with LMS Values. In [http://www.cdc.gov/growthcharts/percentile_data_files. htm] Accessed June 6, 2013.
35. European Paediatric Lipodystrophy Group: Antiretroviral therapy, fat redistribution and hyperlipidaemia in HIV-infected children in Europe. AIDS 2004, 18(10):1443-1451.

36. World Health Organization: Global Price Reporting Mechanism for HIV, Tuberculosis and Malaria. In [http://www.who.int/hiv/amds/gprm/en/] Accessed December 26, 2012

37. Chang S: Addressing the Drug Development Needs of Infants and Young Children: DNDi's Pediatric HIV Program. In 19th Interational AIDS Conference: July 22, 2012 2012; Washington, D.C. ; 2012.

38. World Health Organization: Progress Report 2011: Global HIV/AIDS Response: Epidemic Update and Health Sector Progress Towards Universal Access. In [http://www.who.int/hiv/pub/progress_report2011/en/ index.html] Accessed January 20, 2013.

39. Prendergast AJ, Penazzato M, Cotton M, Musoke P, Mulenga V, Abrams EJ, Gibb DM: Treatment of young children with HIV infection: using evidence to inform policymakers. PLoS Med 2012, 9(7):e1001273.

doi:10.1186/1472-6963-14-201

Cite this article as: Doherty et al: Estimating age-based antiretroviral therapy costs for HIV-infected children in resource-limited settings based on World Health Organization weight-based dosing recommendations. BMC Health Services Research 2014 14:201.

\section{Submit your next manuscript to BioMed Central and take full advantage of:}

- Convenient online submission

- Thorough peer review

- No space constraints or color figure charges

- Immediate publication on acceptance

- Inclusion in PubMed, CAS, Scopus and Google Scholar

- Research which is freely available for redistribution

Submit your manuscript at www.biomedcentral.com/submit
C Biomed Central 